\title{
Morphological and Quantitative Characteristics of the Skin of Holstein Cattle in the Amur Region
}

\author{
Marina E. Ostyakova', Irina Yu. Sayapina², Nikolay M. Mandro³, Natal'ya \\ V. Trush ${ }^{4}$, Yuriy A. Gavrilov ${ }^{5}$, Galina A. Gavrilova ${ }^{6}$, Lopsondorzho V. Hibchenov ${ }^{7}$, Alexey N. Chubin ${ }^{8}$ \\ ${ }^{1}$ The Federal State Budget Scientific Institution "Far Eastern Zonal Research Veterinary Institute", 675000, North Street, 112, city of \\ Blagoveshchensk, Amur Region, Russia \\ ${ }^{2}$ Department of Histology and Biology, FGBOU V Amur State Medical Academy of the Ministry of Health of Russia, 675006, ul. Gorky \\ 95, city of Blagoveshchensk, Amur Region, Russia \\ ${ }^{3}$ Department of veterinary and sanitary examination, epizootology and microbiology, FGBOU VO Far Eastern State University, 675005, \\ ul. Kuznechnaya, 95, city of Blagoveshchensk, Amur Region, Russia \\ ${ }^{4}$ Department of Biology and Hunting, FGBOU VO Far Eastern State University, 675000, ul. Lenina, 180, city of Blagoveshchensk, Amur \\ Region, Russia \\ ${ }^{5}$ Department of Ecology, Soil Science and Agrochemistry, FGBOU VO Far Eastern State University, 675005, ul. Politekhnicheskaya, 86, \\ city of Blagoveshchensk, Amur Region, Russia \\ ${ }^{6}$ Department of Technology of Production and Organization of Public Catering, FGBOU VO Far Eastern State University, 675005, ul. \\ Gor'kogo 90, city of Blagoveshchensk, Amur Region, Russia \\ ${ }^{7}$ Department of Anatomy, Physiology, Pharmacology, FGBOU VO Buryatskaya GSKHA im. V.R. Filippova, 670024, ul. Pushkina, Ulan- \\ Ude, Russia \\ ${ }^{8}$ Veterinary Center, 354057, Tuapse, 5/1, Sochi, Russia \\ *Corresponding author marinaostyakova@yandex.ua
}

\begin{abstract}
The skin of mammals has a high reactivity to the conditions of the external and internal environment. There is no information about the features of the structure of the skin of Holstein cattle in the context of its adaptation to the sharply continental with the symptoms of monsoon climate in the available literature. The purpose of the study was to determine the structural features of the skin of the sternal and costal regions of cattle of the Holstein breed in the Amur region. For the study, the skin of clinically healthy mature Holstein cows was taken. Time of research - autumn. The skin was fixed in a 10\% aqueous solution of neutral formalin. Paraffin sections with a thickness of 5-7 $\mu \mathrm{m}$ were prepared. The sections were stained with hematoxylin and eosin, collagen fibers were detected by the Van Gison method, elastic fibers by Weygert. A distinctive feature of the papillary layer of the dermis was a well-developed system of venous sinuses that anastomosed with each other. The abundance of mononuclear cells in the lumen of the sinuses indicated the important role of the skin as an organ of the immune system that provides adaptation and protection of animals in a sharply continental climate.
\end{abstract}

\section{Introduction}

In modern cattle breeding, the Holstein cattle breed is one of the most widespread and actively used in most countries of the world, the specificity of which is that its effective use is possible only when creating comfortable conditions $[1 ; 5 ; 8$; $11]$.

The organism of animals in uncomfortable conditions within certain limits can withstand the damaging effects of unfavorable factors due to nonspecific and specific protection systems.

Nonspecific protective factors include hematoepithelial barriers, in particular the skin, the structure and properties of which depend on the breed of cattle, hereditary characteristics, age changes, sex differences, conditions of maintenance and feeding $[2 ; 6]$.
According to modern ideas, the skin is a complex labile biocomposite that has high reactivity to the conditions of both the external and internal environment of the organism, which provides structural transformations in it $[7 ; 9 ; 12 ; 14 ; 15 ; 16]$ In the available literature there is no information about the features of the structure of the skin of Holstein cattle in the context of its adaptation to the sharply continental climate of the Amur Region with signs of monsoon.

The purpose of the study was to determine the structural features of the skin of the sternal and costal areas of the Holstein breed cattle in the Amur region.

\section{Material and Methods of Investigation}

The object of the research was the cattle of Holstein breed of black and white colour, imported to the Amur Region in 2010. The material was selected in October 2012, from clinically healthy mature cows older than 24 months. 
In early autumn 2012, the weather was mostly cool with precipitation. The average decadal air temperature was in the northern regions $+10 \ldots+13^{\circ} \mathrm{C}$. The second half of the autumn was characterized by unstable weather conditions. The average air temperature was below the norm by $2-3^{\circ} \mathrm{C}$ and amounted to $-8 \ldots+5^{\circ} \mathrm{C}$ in the northern regions, in the south it varied from $-2 \ldots+8^{\circ} \mathrm{C}[4]$.

Statistica 6.0 software (StatSoft, USA) was used to statistically process quantitative data and all data are presented as $\mathrm{M} \pm \mathrm{m}$. The hypothesis of normal distribution of values in samples was tested using the Kolmogorov-Smirnov test, then the parametric

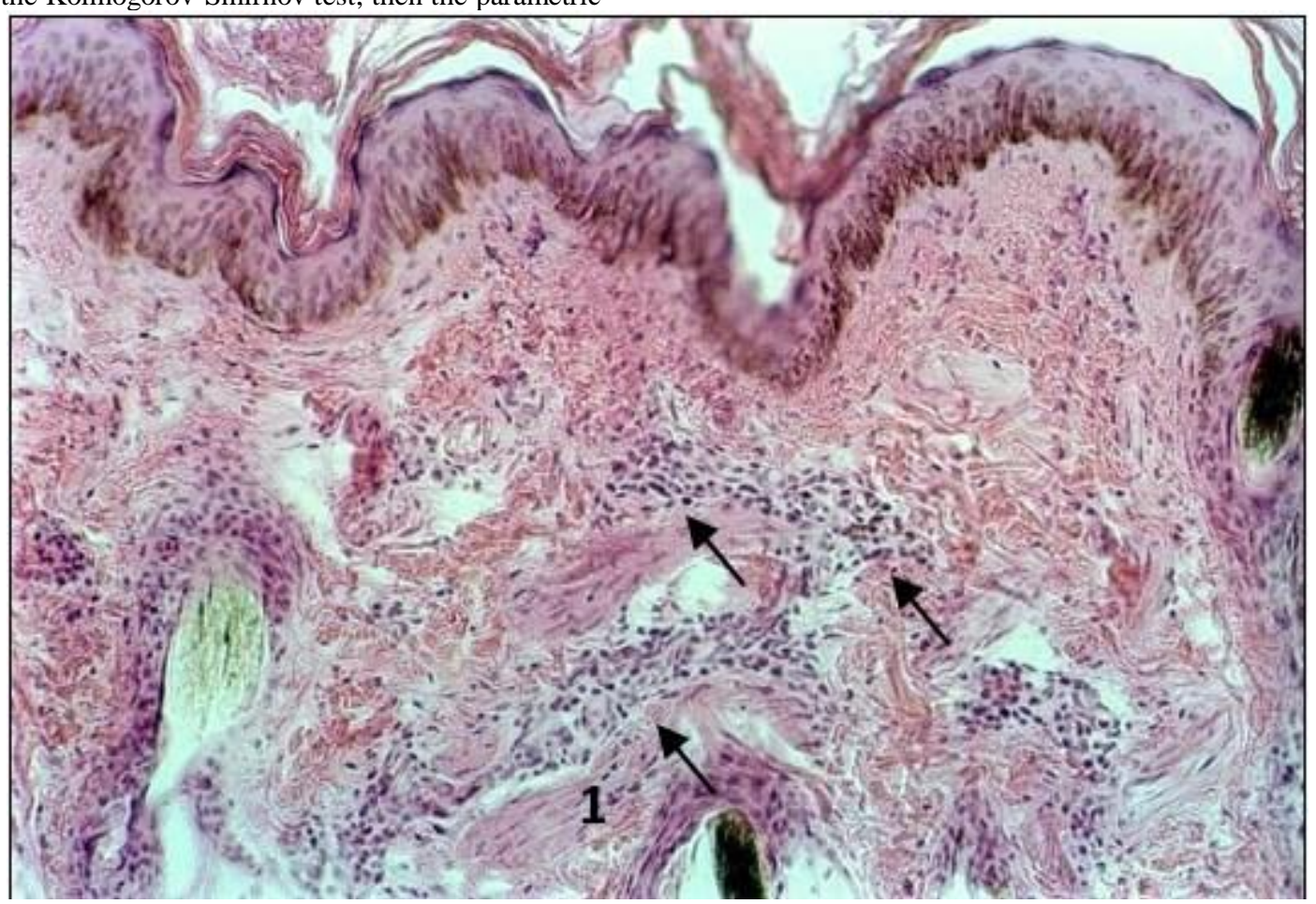

Figure 1. The relief of the skin is represented by epidermal scallops and grooves. The accumulation of mononuclear cells (arrows) in the lumen of the venous sinuses of the net layer of the dermis. 1 - muscle lifting the hair. Stained with hematoxilin and eosin. Magnification: approx. 10, vol.10.

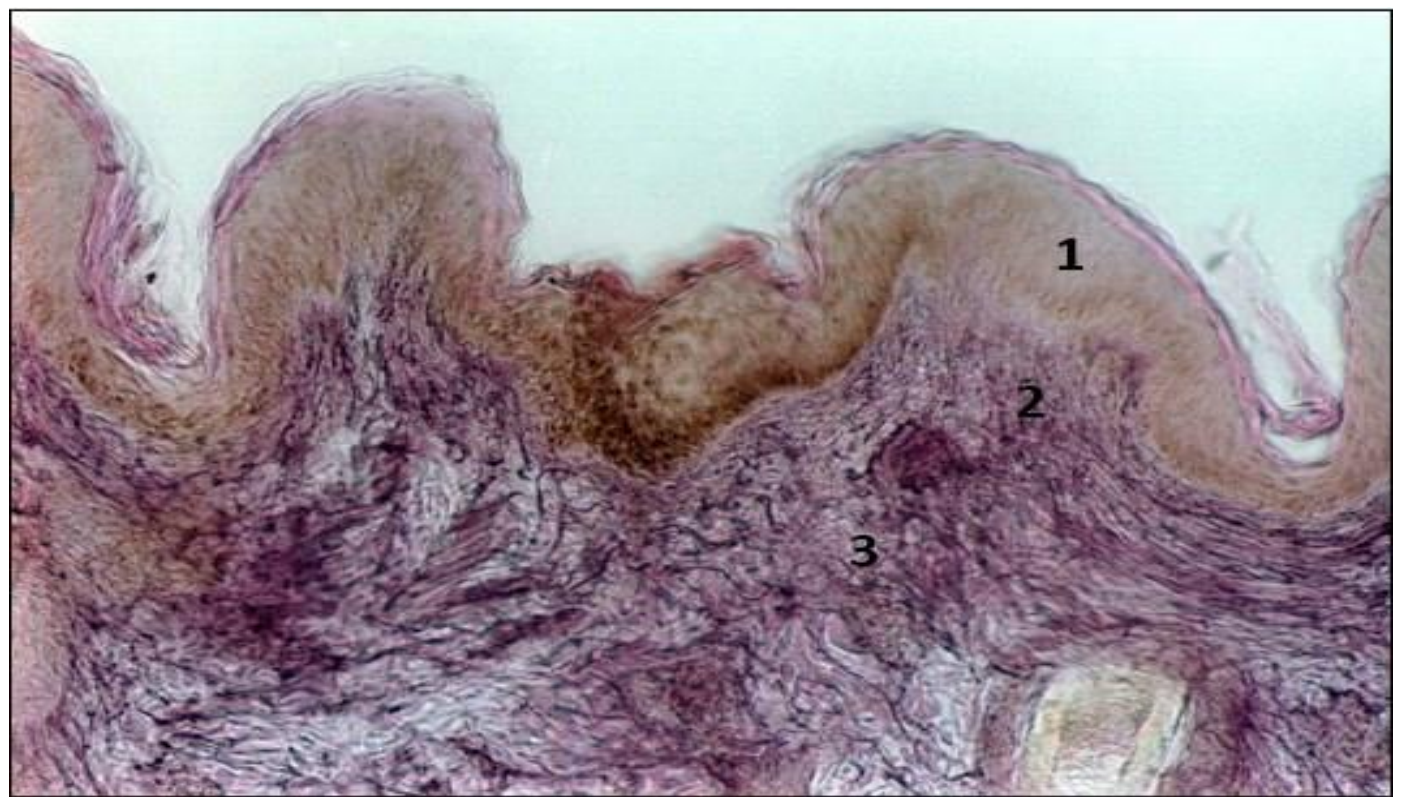

Figure 2. Elastic fibers of the papillary and reticular layers of the dermis. 1-epidermis, 2-papillary layer, 3-mesh layer. Staining by Weigert. Magnification: approx. 10, vol. 20.

The epidermal scallops have a dome-shaped form, rather wide base, the structure of which includes papillary and partially reticulated layers of the dermis (Fig. 3).
Student t-test was used to compare samples. Differences between samples were considered statistically significant at $\mathrm{p}<$ 0.05 .

\section{Own Research}

The skin of cattle has a complex relief represented by epidermal scallops and grooves located between them (Fig. 1,2). 


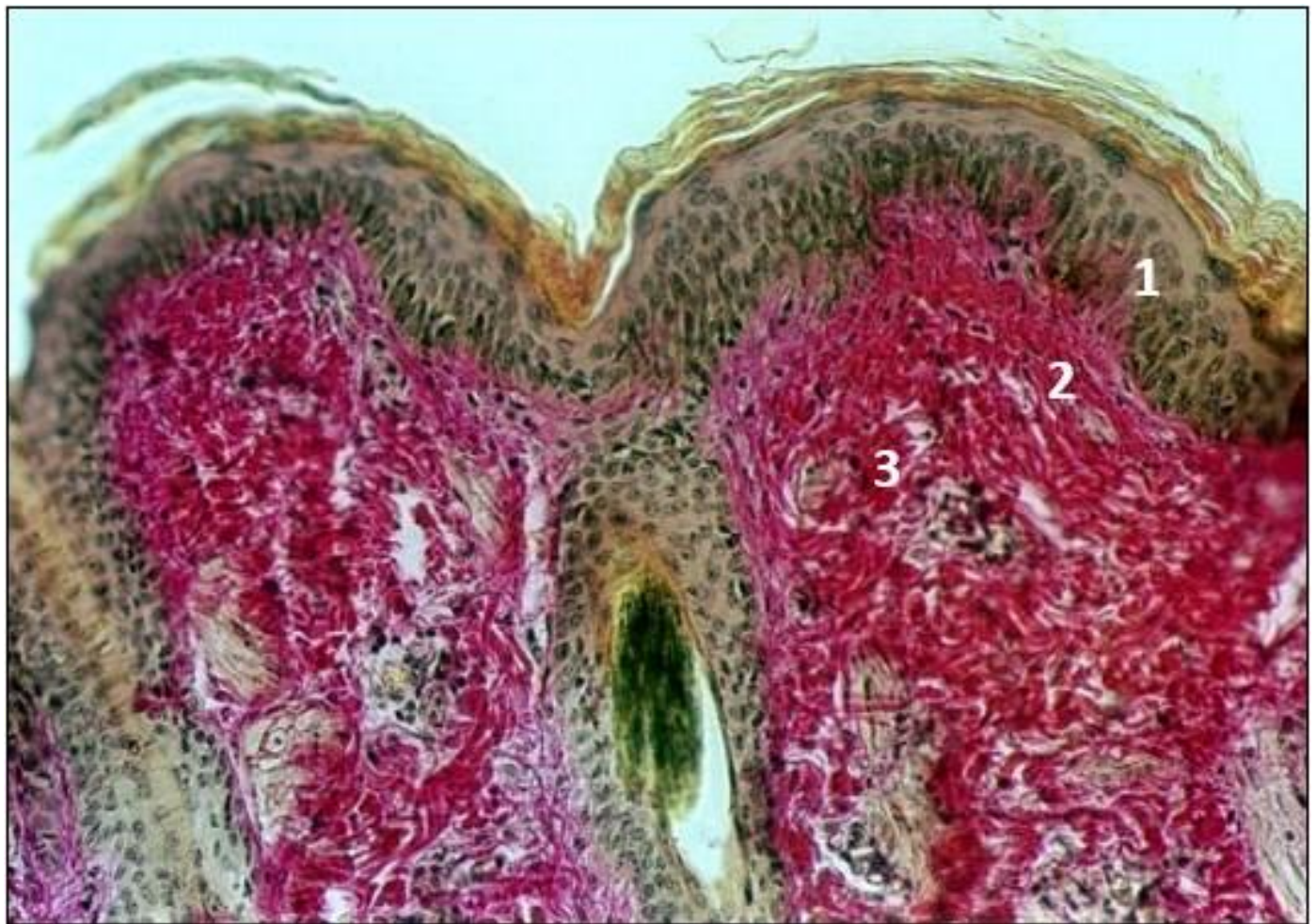

Figure 3. Collagen fibers of the papillary and reticular layers of the dermis. 1 - epidermis, 2 - papillary layer, 3 - mesh layer. Staining by Van Guison. Magnification: about 10, about. 20.

The epidermis is represented by several layers of cells: basal, prickly, granular and horny. Keratocytes of columnar form, located in one layer on the basal membrane, were determined in the basal layer of the epidermis. The cells had oval cores oriented perpendicular to the basal membrane of the epidermis. In the cytoplasm of basal keratinocytes, granules of melanin were detected in large numbers, and cells accumulating more melanin were located in the region of the epidermal scallops. In basal keratinocytes, located in the area of grooves, which penetrate into the dermis, the content of melanosomes decreased.

The spinous layer is formed by several rows of irregular keratinocytes with rounded nuclei. The cytoplasm of the cells of the spinous layer adjacent to the basal keratinocytes also contained melanin granules, as cells moved up the melanin inclusions became less.

The granular layer in the epidermis of cattle is poorly developed. It is represented by strongly flattened keratinocytes arranged in a single layer. The nuclei of cells are relatively large, vesicular, in the cytoplasm were present basophilic colored keratogialin granules. The corneal layer is represented by corneocytes with clearly defined boundaries. On the surface of the epidermal scallops, the stratum corneum is as thin as possible, and in the region of the furrows of the skin, its thickening was noted. At the boundary of the epidermis and the dermis there was a dermo-epidermal junction, below which the papillary layer of the dermis began. This layer in the representatives of the Holstein breed was very thin (table 1).

Table 1. Morphometric parameters of the cattle skin

\begin{tabular}{|l|l|}
\hline Morphometric index & $\mathrm{M} \pm \mathrm{m}$ \\
\hline Number of grooves & $2,5 \pm 0,19(\mathrm{n}=42)$ \\
\hline Number of epidermal scallops & $2,7 \pm 0,19(\mathrm{n}=42)$ \\
\hline Width of epidermal scallops $(\mu \mathrm{m})$ & $403,4 \pm 20,68(\mathrm{n}=145)$ \\
\hline Height of epidermal scallops $(\mu \mathrm{m})$ & $219,4 \pm 8,83(\mathrm{n}=69)$ \\
\hline Thickness of the epidermis $(\mu \mathrm{m})$ & $94,4 \pm 2,04(\mathrm{n}=301)$ \\
\hline The thickness of the papillary layer of the dermis $(\mu \mathrm{m})$ & $148,9 \pm 3,61(\mathrm{n}=244)$ \\
\hline Thickness of the mesh layer of the dermis $(\mu \mathrm{m})$ & $1161,4 \pm 18,94(\mathrm{n}=89)$ \\
\hline Number of papillae at $1172 \mu \mathrm{m}$ & $14,1 \pm 0,37(\mathrm{n}=41)$ \\
\hline Width of papillae $(\mu \mathrm{m})$ & $51,9 \pm 1,05(\mathrm{n}=301)$ \\
\hline Height of papillae $(\mu \mathrm{m})$ & $58,2 \pm 1,39(\mathrm{n}=286)$ \\
\hline The diameter of the acini of the sebaceous glands $(\mu \mathrm{m})$ & $83,1 \pm 1,76(\mathrm{n}=128)$ \\
\hline Diameter of peripheral nerves $(\mu \mathrm{m})$ & $38,8 \pm 1,12(\mathrm{n}=98)$ \\
\hline
\end{tabular}

Papillary layer in the form of small and irregularly located dermal papillae penetrated into the epidermis, giving a complex relief of its internal surface. The epidermis, in turn, deepened into the underlying dermis in the form of shallow epidermal ridges, or intergrowth wedges (Figure 1, 3).

Despite the fact that the papillary layer of the dermis is formed by a loose fibrous unformed connective tissue, the tendency towards an ordered arrangement of collagen fibers was traced in the skin of cattle. The main part of the collagen fibers was located in the tangential plane, repeating the contours of the inner surface of the epidermis. Near the epidermis, collagen fibers were located as compact as possible, but as they approached the mesh layer they thicken and lose order, being more loosely and chaotically (Fig. 1, 3).

Elastic fibers in the papillary layer of the dermis were located between the collagen fibers parallel to the epidermis, and at the level of the dermal papillae rushed upwards, weaving into the network of fibers of the dermo-epidermal junction (Fig. 2). Between the fibrous structures of the papillary layer were numerous blood vessels of the microcirculatory bed and 
morphologically unidentifiable at small increases in the microscope cells of connective tissue (Fig. 1, 3).

The mesh layer of the dermis was 7.8 times greater than the papillary one. In the mesh layer, the predominance of fibrous structures predominantly represented by thick bundles of collagen fibers moving in a different direction was noted (Figures 1, 3). In the upper third of the mesh layer there were numerous elastic fibers, some of which lay between collagen fibers, repeating their direction (Fig. 2). In the middle and lower third of the mesh layer, elastic fibers in the skin of cattle were practically absent.

In the dermis of the skin, two vascular plexuses were found, located parallel to the surface of the skin. The deep dermal plexus, located in the deepest layers of the papillary dermis, contained arteries and veins of large caliber, near which were located peripheral nerves. The diameter of the peripheral nerves, as a rule, correlated with the diameter of the accompanying blood vessels, the epineurium is poorly developed (Figure 4).

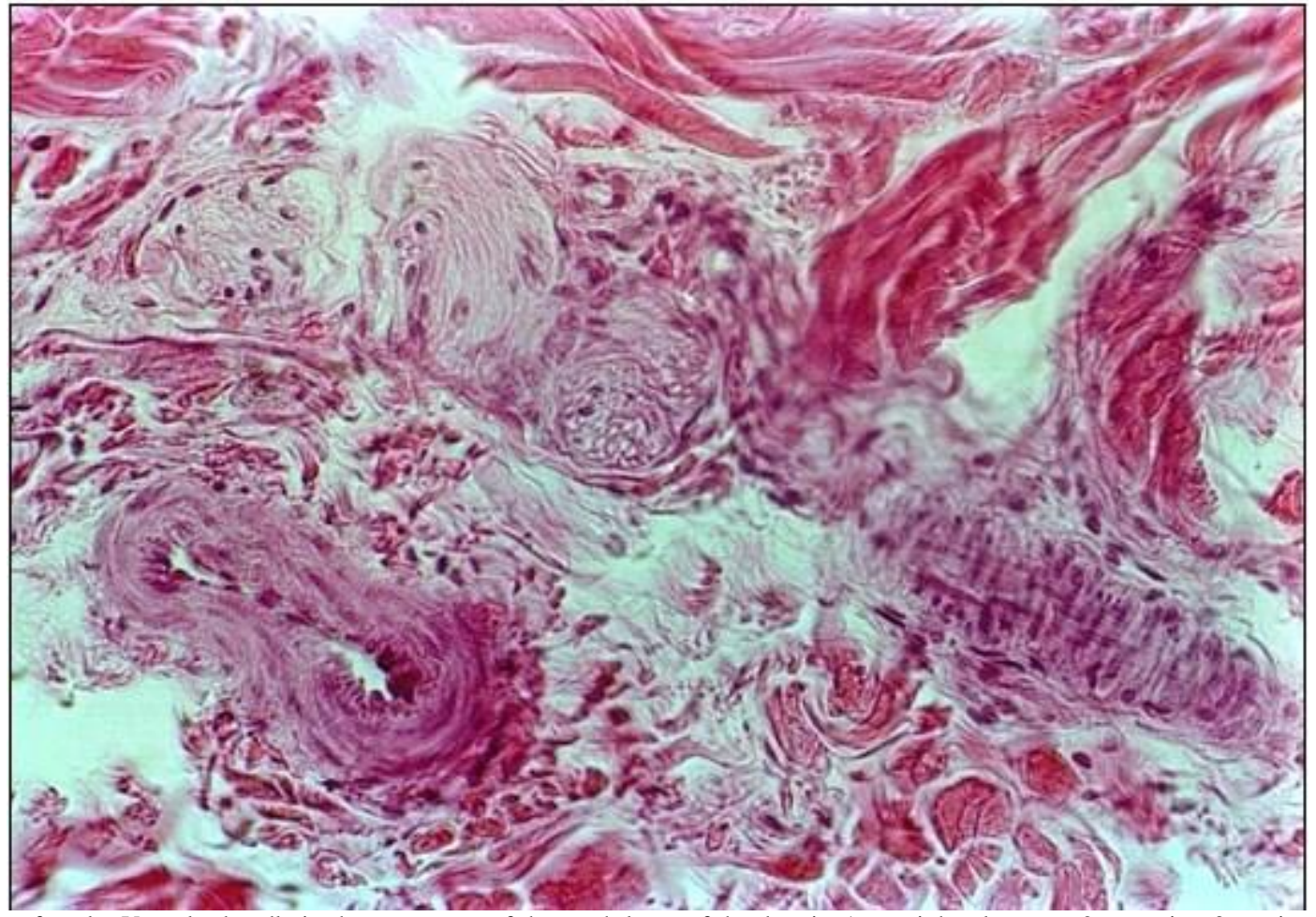

Figure 4. Skin of cattle. Vascular bundle in the upper part of the mesh layer of the dermis. 1 - peripheral nerves, 2 - arteries, 3 - veins. Staining with hematoxylin and eosin. Magnification: approx. 10, v/ v. 40.

The branches of the deep dermal arterial plexus were sent strictly upward, piercing the entire thickness of the mesh layer, forming in its upper part a superficial arterial network. Arteries of the superficial arterial network, located in the upper part of the papillary layer, had a linear course. In the middle third of the dermis, horizontal branches of vertical arteries can be observed, reaching the hair follicles and the terminal sections of the sebaceous glands.

The venous bed in the upper third of the mesh layer was characterized by an abundance of venous sinuses forming an anastomosing network. In the lumens of venous sinuses, there was an abundance of mononuclear cells, in terms of its phenotypic characteristics resembling lymphocytes.

From the derivatives of the skin in the mesh layer were located hair follicles and sebaceous glands. Hair follicles had the usual structure, the central position in them occupied hair, represented by intensely pigmented cortical and lighter brain substance, surrounded by internal and external epithelial vaginas. Outside, the hair follicles are covered with a hair bag from the connective tissue into which the bundles of smooth myocytes that form the muscle lifting the hair are interwoven (Figure 1).

The most common variant of the structure of the sebaceous glands was the presence of two large unbranched end sections, located to the left and right of the hair follicle, the output ducts of which opened into the follicular canal at the level of the middle third of the dermis. Smaller branched secretory departments of the alveolar type, consisting of two or more acinuses were much less common.
The hypoderma in the skin of cattle of Holstein breed was practically absent, as a result of which the muscle fibers separated from the last layer by a thin layer of connective tissue were observed below the level of the mesh layer.

\section{Discussion}

The weather in the autumn months in the Amur region was characterized as unstable, with sharp temperature changes during the day and night hours and precipitation [4]. Such temperature environmental stimuli, even mild ones, have an irritating effect on the sensitive nerves of the microcirculatory bed of animal skin, and also activate the hypothalamicpituitary-adrenal system $[17 ; 21]$.

In the blood and other body fluids, the level of stress hormones increases significantly: adrenaline, norepinephrine, glucagon, corticoids. The influence of the sympathetic nervous system is increasing. Heart work is stimulated, which leads to an increase in heart rate and cardiac output, which may be the cause of blood flow to the skin without the influence of local regulatory factors [19]. At the same time, prostaglandins, adenosine, acetylcholine, factors of antioxidant protection have a stressful effect in the peripheral organs and tissues, preventing a stressdependent ischemia [3].

The study of the mesh layer of the skin of Holstein cattle revealed an abundance of venous sinuses forming an anastomosing network, that is, there was hypertrophy of structural elements of organs and tissues, providing the 
development of increased resistance of the animal organism, which is characteristic of long-term adaptation [19].

The skin contains a large number of circulating T-lymphocytes that promote adaptive immune tolerance of the skin to the action of conditionally pathogenic microflora $[13 ; 16]$.

The abundance of mononuclear cells around the venous sinuses of the mesh layer of the Holstein cattle dermis testified to the mobilization of the system of immunobiological supervision in a sharply continental climate.

The large amount of melanin found in the cytoplasm of the basal keratinocytes of the epidermis of the Holstein cattle skin is a photoprotective characteristic and reflects its adaptation to the environment $[18 ; 20]$.

When studying the architectonics and density of the dermis fibers, a more loose and chaotic arrangement of the collagen fibers near the mesh layer were noted. The decrease in the density of the ligament plays the role of structural and compensatory adaptations, which are aimed at maintaining the biochemical characteristics of the skin as a natural biopolymer [10].

\section{Conclusion}

Thus, the skin of the sternal and costal areas of cattle of the Holstein breed was characterized by a complex relief due to the alternation of epidermal scallops and grooves.

Features of the epidermis was a good pigmentation of keratinocytes of the basal layer and the maximum thinning of the granular layer.

The presence of a thin papillary layer of dermis in conjunction with a thickened mesh layer was a morphological feature of the high strength of the skin in the representatives of this breed of cattle.

The most common variant of the structure of the sebaceous glands was the presence of two large unbranched end sections, located to the left and right of the hair follicle.

A distinctive feature of the papillary layer of the dermis was a well-developed system of venous sinuses, anastomosing among themselves. The abundance of mononuclear cells in the sinus lumen indicated the important role of the skin as an organ of the immune system, providing adaptation and protection of animals in the Amur region.

\section{References}

[1] Belkov, G. I., Panin, V. A. (2017). Some indicators of stress resistance of Simmental breed cows and Holstein Simmental hybrids. Proceedings of the Orenburg State Agrarian University. No. 6 (68). 157-160.

[2] Kibkalo, L. I., Zherebilov, N. I. (2009). Quality of raw hides of cattle. Bulletin of the Kursk State Agricultural Academy. No. 4. 63-67.

[3] Litvitsky, P. F. (2010). Disorders of the body's heat balance: hyperthermia, hyperthermic reactions, heat stroke, sunstroke. Questions of modern pediatrics. No. 9 (1). 96-102.

[4] Review of the phytosanitary condition of agricultural crops in the Amur Region and the forecast for the development of harmful facilities in 2013. Blagoveshchensk, 2013. 46.

[5] 5.Osadchuk, L. V., Sebasco, O. I., Shishin, N. G., Korotkevich, O. S., Konovalova, T. V., Petukhov, V. L., Fikhman, E. V. (2017). Hormonal and metabolic status of Holstein breeds bullcalves in ecological and climatic conditions of the Kemerovo region. Vestnik of Novosibirsk state agrarian University. 2 (43). 2017. 52-61.

[6] Panin, V. A. (2018). Some biological features of animals of Simmental breed and Holstein Simmental hybrids. News of the Orenburg state agrarian University. № 1 (69). 176-179.

[7] Pozdnyakov, V. F., Soboleva, O. V., Smirnova, I. A., Pravilova, E. A. (2015). Dynamics of skin and hair of cattle in their adaptation to resource-saving technologies. Modern problems of science and education. № 4 .

[8] Svaitina, M. A., Ponomarev, E. A. (2017). Holstein cattle in the North. News of the Orenburg state agrarian University. № 5. 163-166.

[9] Slesarenko, N. A. (2015). Structural and biochemical basis of adaptive plasticity of fur animals ' skin. Idols. Russian veterinary journal. № 4. 12-13.

[10] Slesarenko, N. A., Stephanishin, V. V. (2015). Mirtazapine restructuring of the skin of the sable in the conditions of stimulation of growth processes. News of the Orenburg state agrarian University. № 5. 105-108.

[11] Sharafutdinova, E. B., Rostov, N. Yu. (2016). Adaptive reaction of imported Holstein cattle to the temperature conditions of the environment. Proceedings of the Orenburg state agricultural UNIVERSITY. № 2. 2016. 156-159.

[12] Ahmed, B. M. S., Younas, U., Asar, T. O., Dikmen, S., Hansen, P. J., \& Dahl, G. E. (2017). Cows exposed to heat stress during fetal life exhibit improved thermal tolerance. Journal of animal science, 95(8), 3497-3503.

[13] Ali, N., Rosenblum, M. D. (2017). Regulatory T cells in skin. Immunology. 152(3), 372-381.

[14] Ardesjö-Lundgren, B., Tengvall, K., Bergvall, K., Farias, F. H., Wang, L., Hedhammar, ^., ... \& Andersson, G. (2017). Comparison of cellular location and expression of Plakophilin-2 in epidermal cells from nonlesional atopic skin and healthy skin in German shepherd dogs. Veterinary dermatology, 28(4), 377.

[15] Bidaux, G., Borowiec, A. S., Gordienko, D., Beck, B. Shapovalov, G. G., Lemonnier, L., ... \& Delcourt, P. (2015). Epidermal TRPM8 channel isoform controls the balance between keratinocyte proliferation and differentiation in a colddependent manner. Proceedings of the National Academy of Sciences, 112(26), E3345-E3354.

[16] Honda, T., \& Kabashima, K. (2017). In vivo imaging of cutaneous inflammation: novel insights into cutaneous immune responses revealed by multi-photon microscopic analysis. Nihon Rinsho Men'eki Gakkai kaishi= Japanese journal of clinical immunology, 40(5), 337-343.

[17] Kodji, X., Aubdool, A. A., \& Brain, S. D. (2016). Evidence for physiological and pathological roles for sensory nerves in the microvasculature and skin. Current research in translational medicine, 64(4), 195-201.

[18] Morales-Guerrero, B., Barragán-Vargas, C., Silva-Rosales, G. R., Ortega-Ortiz, C. D., Gendron, D., Martinez-Levasseur, L. M., \& Acevedo-Whitehouse, K. (2017). Melanin granules melanophages and a fully-melanized epidermis are common traits of odontocete and mysticete cetaceans. Veterinary dermatology, 28(2), 213.

[19] Paparde, A., Plakane, L., Circenis, K., \& Aivars, J. I. (2015). Effect of acute systemic hypoxia on human cutaneous microcirculation and endothelial, sympathetic and myogenic activity. Microvascular research, 102, 1-5.

[20] Sugaya, K. (2017). Effects of gamma rays on the regeneration of murine hair follicles in the natural hair cycle. International journal of radiation biology, 93(9), 937-946.

[21] Vandeleest, J. J., Blozis, S. A., Mendoza, S. P., \& Capitanio, J. P. (2013). The effects of birth timing and ambient temperature on the hypothalamic-pituitary-adrenal axis in 3-4 month old rhesus monkeys. Psychoneuroendocrinology, 38(11), 2705 2712 . 